\title{
Prediction of Compressive Strength Behavior of Ground Bottom Ash Concrete by an Artificial Neural Network
}

\author{
Kraiwut Tuntisukrarom (iD) and Raungrut Cheerarot $(\mathbb{D})$ \\ Concrete and Computer Research Unit, Civil Engineering, Faculty of Engineering, Mahasarakham University, Kantharawichai, \\ Mahasarakham 44150, Thailand \\ Correspondence should be addressed to Raungrut Cheerarot; raungrut@hotmail.com
}

Received 2 December 2019; Revised 19 February 2020; Accepted 6 May 2020; Published 1 June 2020

Academic Editor: Fuat Kara

Copyright ( 92020 Kraiwut Tuntisukrarom and Raungrut Cheerarot. This is an open access article distributed under the Creative Commons Attribution License, which permits unrestricted use, distribution, and reproduction in any medium, provided the original work is properly cited.

\begin{abstract}
The objective of this work was to examine the compressive strength behavior of ground bottom ash (GBA) concrete by using an artificial neural network. Four input parameters, specifically, the water-to-binder ratio (WB), percentage replacement of GBA (PR), median particle size of GBA (PS), and age of concrete (AC), were considered for this prediction. The results indicated that all four considered parameters affect the strength development of concrete, and GBA with a high fineness can act as a good pozzolanic material. The optimal ANN model had an architecture with two hidden layers, with six neurons in the first hidden layer and one neuron in the second hidden layer. The proposed ANN-based explicit equation represented a highly accurate predictive model, for which the statistical values of $R^{2}$ were higher than 0.996 . Moreover, the compressive strength behavior determined using the optimal ANN model closely followed the trend lines and surface plots of the experimental results.
\end{abstract}

\section{Introduction}

Artificial neural networks (ANNs) have been widely applied owing to the excellent performance of the associated highaccuracy predictive model in learning and analyzing the effects of the input and output variables. In particular, ANN models are valuable tools for predicting experimental results. In the field of concrete engineering, for the experimental datasets of concrete properties, an ANN model was proposed to predict the compressive strength of concrete containing pozzolanic materials such as fly ash, silica fume, metakaolin, and ground granulated blast furnace slag [1-3]. In addition, the ANN model has been extended for predicting the properties of concrete, for instance, workability, corrosion currents, split tensile strength, water permeability, and chloride permeability [4]. Many studies have reported that ANN models lead to a more accurate and precise prediction than that obtained using linear and nonlinear regression techniques, and it can be easily expanded to new additional databases, enabling the retraining of the network [2-4].
Bottom ash (BA) is a byproduct of the combustion of powder coal in an electric power plant. In particular, fly ash (FA) is melted at high temperatures, and it agglomerates to form $\mathrm{BA}$ at low temperatures. $\mathrm{BA}$ is similar to $\mathrm{FA}$; however, BA has a considerably larger particle size, and thus it cannot be used as a cementitious material in concrete. Ghafoori and Cai $[5,6]$ studied BA as a fine aggregate and reported the behavior of laboratory-made roller-compacted concrete (RCC) containing BA. The RCC containing BA exhibited excellent strength, stiffness, durability, and deformation properties. Furthermore, Ghafoori and Bucholc $[7,8]$ used dry BA as a fine aggregate in concrete and indicated that the amount of required mixing water increased rapidly with the increase in the BA content. Other researchers used BA with low density as an aggregate in lightweight concrete to decrease the concrete density.

Compressive strength is one of the most important properties of mortar or concrete. Many researchers $[9,10]$ studied the mechanism analysis of hydration and pozzolanic reaction which found that when cement and pozzolanic material were mixed with water, cement clinker minerals 
hydrate first, to release $\mathrm{Ca}(\mathrm{OH})_{2}$ crystal, producing the alkalinity solution. Then, the active compound of pozzolanic material reacted with $\mathrm{Ca}(\mathrm{OH})_{2}$ to produce the calcium silicate hydrate and calcium aluminate hydrate, resulting in reducing of $\mathrm{Ca}(\mathrm{OH})_{2}$ content in the solution; thus the hydration of cement clinker was accelerated. The later subsequent hydration reaction equations could be expressed as

$$
\mathrm{x} \mathrm{Ca}(\mathrm{OH})_{2}+\mathrm{SiO}_{2}+\mathrm{nH}_{2} \mathrm{O}=\mathrm{x} \mathrm{CaO} \cdot \mathrm{SiO}_{2} \mathrm{O}(\mathrm{n}+\mathrm{x}) \mathrm{H}_{2} \mathrm{O}
$$

$\mathrm{x} \mathrm{Ca}(\mathrm{OH})_{2}+\mathrm{Al}_{2} \mathrm{O}_{3}+\mathrm{mH}_{2} \mathrm{O}=\mathrm{x} \mathrm{CaO} \cdot \mathrm{Al}_{2} \mathrm{O}_{3} \cdot(\mathrm{m}+\mathrm{x}) \mathrm{H}_{2} \mathrm{O}$

In the formula, if $x \leq 3$,

$$
\begin{aligned}
& 3 \mathrm{Ca}(\mathrm{OH})_{2}+\mathrm{Al}_{2} \mathrm{O}_{3}+2 \mathrm{SiO}_{2}+\mathrm{mH}_{2} \mathrm{O}=3 \mathrm{CaO} \cdot \mathrm{Al}_{2} \mathrm{O}_{3} \\
& \cdot 2 \mathrm{SiO}_{2} \cdot(\mathrm{m}+3) \mathrm{H}_{2} \mathrm{O}
\end{aligned}
$$

Equations (1)-(3) express the pozzolanic reaction, in which both $\mathrm{C}-\mathrm{S}-\mathrm{H}$ and $\mathrm{C}-\mathrm{A}-\mathrm{H}$ enhance the compressive strength of concrete. The fineness of pozzolanic materials is one of the most important physical properties that affect the pozzolanic reaction. Therefore, increasing the fineness of the BA can help enhance the quality of concrete. Consequently, in this research, three sizes of GBA were considered to investigate the corresponding influence on the compressive strength of concrete.

An investigation of the original BA [9] indicated that the median particle size $\left(d_{50}\right)$ and percentage of retained particles on sieve number 325 were approximately $300 \mu \mathrm{m}$ and $95 \%$, respectively. The strength activity indices of the original BA mortar at the ages of 7 and 28 days were $46 \%$ and $49 \%$ of the standard mortar, respectively, and its water requirement was $114 \%$. In its original form, the BA cannot be used as a pozzolanic material to replace Portland cement in concrete mixtures owing to its large particle size (compared to that of cement) and porous structure, as these aspects may lead to an undesirable degradation of the properties of fresh and hardened concrete. However, several studies $[4,10]$ reported that BA could be ground, thereby obtaining the necessary properties for BA to be used as partial replacement of cement in concrete mixtures. In particular, the decrease in the particle size of BA increases its pozzolanic activity and helps improve the mechanical and physical properties of concrete.

To this end, the objective of this work was to examine the effect of the water-to-binder ratio (WB), percentage replacement of GBA (PR), median particle size of GBA (PS), and age of concrete (AC) on the compressive strength of GBA concrete. Furthermore, on the basis of this experimental data, a neural network was established to derive an explicit equation to predict the compressive strength of GBA concrete.

\section{Experimental Database}

2.1. Materials. Experimental ASTM type-I ordinary Portland cement and BA from Mae Moh power plant in northern
Thailand were employed in this work. The chemical compositions of the cementitious materials are presented in Table 1, and their physical properties are listed in Table 2. The specific gravity of cement was 3.14 , with a median particle size $\left(d_{50}\right)$ of $11.3 \mu \mathrm{m}$. The portion of the major oxide $\left(\mathrm{SiO}_{2}+\mathrm{Al}_{2} \mathrm{O}_{3}+\mathrm{Fe}_{2} \mathrm{O}_{3}\right)$ of the $\mathrm{BA}$ was $78.97 \%$, which is higher than the minimum requirement of $70 \%$ specified by ASTM C 618 [11] for class F (as FA). To modify the properties of BA, it was ground using a ball mill until the GBA exhibited three sizes: small (SB), medium (MB), and large (LB). The corresponding median particle sizes were 6.3, 13.6, and $22.2 \mu \mathrm{m}$, and the size of the particles retained on sieve number 325 were $4.9 \%, 18.3 \%$, and $33.6 \%$ by weight, respectively. The fine and coarse aggregate (crushed limestone) had specific gravity values of 2.58 and 2.61 with fineness moduli of 3.1 and 7.2, respectively. The maximum size for the coarse aggregate was $20 \mathrm{~mm}$.

2.2. Mixture Proportions. The control concretes were designed with water to obtain cement ratios of $0.43,0.48$, $0.55,0.62,0.70$, and 0.80 . Portland cement was replaced by different sized GBA in proportions of $0 \%, 10 \%, 20 \%, 30 \%$, $40 \%$, and $50 \%$ by weight of the binder. In all the cases, the concrete mix included $195 \mathrm{~kg} / \mathrm{m}^{3}$ of water as a constant value, and the workability was maintained by using a slump of fresh concrete with values ranging from 80 to $120 \mathrm{~mm}$. The mix proportions of all concrete mixes are summarized in Table 3.

2.3. Compressive Strength Test. The concrete specimens were cast in $100 \times 200 \mathrm{~mm}$ cylindrical molds. Then, these specimens were molded for $24 \mathrm{~h}$ and cured in water at $23 \pm 2^{\circ} \mathrm{C}$ until the testing age. In all the mixtures, the tests were performed on triplicate specimens, the average values were reported, and all the samples were tested for compressive strength at $3,7,14,28,60,90$, and 180 days. The compressive strength of the specimen was calculated by dividing the maximum load attained during the test by the cross-sectional area of the specimen, as specified in ASTM C39/C39$12 \mathrm{a}[12]$.

\section{Artificial Neural Network}

The ANN can be defined as a mathematical model of reasoning, and it was biologically inspired and copied based on the human brain, whose architecture is commonly a basis of the feed-forward neural network (also known as a multilayer perceptron) with an input layer, one or more hidden layers, and an output layer. The learning rules of an ANN (training algorithm) are most commonly established using the gradient descent training algorithm (also known as the backpropagation technique) by modifying the weights and biases according to the error from a network to adjust the actual outputs near the target outputs. In such a method, each node receives weighted inputs from other nodes and communicates its outputs to other nodes by using an activation function. During the learning process, the nodes in each layer are connected to those in the immediate next layer via a 
TABLE 1: Chemical composition of ground bottom ash.

\begin{tabular}{lc}
\hline Chemical composition (\%) & Ground bottom ash \\
\hline $\mathrm{SiO}_{2}$ & 46.02 \\
$\mathrm{Al}_{2} \mathrm{O}_{3}$ & 22.31 \\
$\mathrm{Fe}_{2} \mathrm{O}_{3}$ & 10.64 \\
$\mathrm{CaO}$ & 11.48 \\
$\mathrm{MgO}$ & 3.47 \\
$\mathrm{Na}_{2} \mathrm{O}$ & 0.07 \\
$\mathrm{~K}_{2} \mathrm{O}$ & 3.47 \\
$\mathrm{SO}_{3}$ & 1.52 \\
$\mathrm{LOI}$ & 2.72 \\
\hline
\end{tabular}

cyclic link. The connection links that provide the weights are usually designed to minimize the error in a training algorithm. Finally, the target values of this training algorithm produce the output values of the predicted model. For more detailed information regarding the $\mathrm{ANN}$, the readers can refer to textbooks $[13,14]$ and the existing literature $[15,16]$. Nevertheless, for convenience, the explicit mathematical equation with the results of the output, weight, and bias values of the ANN model used in this study is described in the subsequent section.

3.1. Evaluation of Model Performance. Statistics-based methods [17-19] can be used to compare the predictive performance of several models and select a robust model. Herein, the model prediction accuracy was determined by calculating the absolute fraction of variance $\left(R^{2}\right)$, root mean square error (RMSE), and mean absolute percentage error (MAPE). $R^{2}$ is a measure of the proportion of the total variation in the dataset; $R^{2}$ lies between 0 and 1 , where a value of 1 corresponds to a higher predictive power of the model. The RMSE is the average distance of a data point from the expected value. The MAPE is a measure of the prediction accuracy of the model. The RMSE and MAPE range from 0 to $\infty$, and lower values indicate a better mode fit. However, the MAPE cannot be used if there exist values with no error, involving division by zero occurs. The three statistics measures are expressed as follows:

$$
\begin{aligned}
R^{2} & =1-\left[\frac{\sum_{j=1}^{n}\left(T_{j}-M_{j}\right)^{2}}{\sum_{j=1}^{n}\left(T_{j}\right)^{2}}\right], \\
\mathrm{RMSE} & =\sqrt{\frac{1}{n} \sum_{j=1}^{n}\left(T_{j}-M_{j}\right)^{2}, \text { MAPE }=\frac{100}{n} \sum_{j=1}^{n}\left(\left|\frac{T_{j}-M_{j}}{T_{j}}\right|\right),}
\end{aligned}
$$

where $n$ is the number of experimental dataset, $M$ is the measured value, and $T$ is the target value.

3.2. ANN Architecture Design. The neural network models are developed using MATLAB software. Therefore, there are several learning algorithms, activation functions, and network performances in this software. The performance of the ANN model primarily depends on the network architecture and parameter settings. In this study, the parameter settings in the ANN model are shown in Table 4, and Table 5 shows the range values and numerable parameters of the experiment and prediction. Four factor parameters constitute the input layer: the water-to-binder ratio (WB of $0.43,0.48,0.55$, $0.62,0.70$, and 0.80 ), percentage replacement of ground bottom ash (PR of $0,10,20,30,40$, and 50\%), median particle sizes of ground bottom ash (PS of 6.3, 13.6, and $22.2 \mu \mathrm{m}$ ), and ages of concrete (AC of $3,7,14,28,60,90$, and 180 days); the compressive strength of ground bottom ash (GBA) concrete is the output layer. The data in the ANN models were obtained from laboratory experiments and trained and tested using 631 and 125 sets of experimental data for the model, respectively.

Bayesian regularisation (BR) learning algorithm was used to perform the training process for the ANN model in the MATLAB software. Meanwhile, the network performance function of the sum squared error (SSE) was measured to search the best technique based on the statistic value of $R^{2}$ to minimize the error between the actual output and the target output [1-4]. Log-sigmoid, tan-sigmoid, and purelin linear activation functions were used to evaluate their performance against the model mean squared values [20]. There activation functions are defined in

$$
\begin{gathered}
\tan -\text { sigmoid: } g(x)=\frac{2}{1+e^{-2 x}}-1, \\
\text { log - sigmoid: } g(x)=\frac{1}{1+e^{-x}}, \\
\text { purelin: } g(x)=x .
\end{gathered}
$$

The optimal ANN model was determined among the architectures that consisted of one hidden layer with 4-14 neurons or two hidden layers with 4-14 neurons in the first hidden layer and 1-2 neurons in the second hidden layer. The optimal ANN model was obtained with high performance in 3 steps. First, the high-accuracy predictive model is guaranteed by both training and testing datasets with statistical values of $R^{2}$ higher than of 0.99. Second, an explicit model equation is reported in this paper. Finally, the reliable compressive strength behavior is confirmed using the sensitivity analysis illustrated by two-dimension (2D) plots and three-dimension (3D) plots to compare the experimental and predictive results. This result shows that the optimal ANN model predicts the concrete compressive strength that closely matches and follows the trend lines and surface plots of the experimental results.

\section{Results and Discussion}

The relationships of the four factor parameters (WB, PR, $\mathrm{PS}$, and $\mathrm{AC}$ ) that can potentially affect the compressive strength (CS) of GBA concrete were considered as the four-parameter input and one-parameter output variables in the ANN-modeled analysis. The amount and range values of these experimental parameters are presented in Table 5 . 
TABLe 2: Physical properties of materials.

\begin{tabular}{lccc}
\hline Sample & Specific gravity & Median particle size, $d_{50}(\mu \mathrm{m})$ & Retained on sieve number $325(\%)$ \\
\hline Cement & 3.14 & 11.3 & 13.2 \\
SB & 2.82 & 6.3 & 4.9 \\
MB & 2.79 & 13.6 & 18.3 \\
LB & 2.77 & 22.2 & 33.6 \\
\hline
\end{tabular}

TABLE 3: Materials compositions for different mixes at 0-50\% replacement with GBA.

\begin{tabular}{cccccc}
\hline WB & Cement $\left(\mathrm{kg} / \mathrm{m}^{3}\right)$ & $\mathrm{GBA}\left(\mathrm{kg} / \mathrm{m}^{3}\right)$ & Water $\left(\mathrm{kg} / \mathrm{m}^{3}\right)$ & Sand $\left(\mathrm{kg} / \mathrm{m}^{3}\right)$ & $789-793$ \\
\hline 0.80 & $244-122$ & $0-122$ & 195 & $770-764$ & $1024-1016$ \\
0.70 & $279-140$ & $0-140$ & 195 & $1951-733$ & $1024-1015$ \\
0.62 & $315-158$ & $0-158$ & 195 & $708-700$ & $1024-1014$ \\
0.55 & $355-178$ & $0-178$ & 195 & $665-656$ & $1024-1012$ \\
0.48 & $406-203$ & $0-203$ & 195 & $626-617$ \\
0.43 & $454-227$ & $0-227$ & & $1024-1010$ \\
\hline
\end{tabular}

GBA: ground bottom ash.

TABLE 4: The adjustment parameters used in the ANN models.

\begin{tabular}{lc}
\hline Adjustment parameters & ANN models \\
\hline Number of input layer units & 4 \\
Number of first hidden layer units & $4: 1: 14$ \\
Number of second hidden layer units & $1: 1: 2$ \\
Number of output layer units & 1 \\
Number of epochs & $500: 500:$ \\
Performance goal & 20,000 \\
Momentum rate & $1.00 E-06$ \\
Learning rate & Default \\
Training algorithm & Default \\
& BR \\
Activation function in hidden layer & Log-sigmoid \\
& and tan- \\
Activation function in output layer & sigmoid \\
Network's performance & Purelin linear \\
\hline
\end{tabular}

4.1. Experimental Results. All the 177 graphs of 3D plots were established using 756 sets of experimental data. The number of experimental $3 \mathrm{D}$ plots can be calculated as follows:

$$
\begin{aligned}
\mathrm{N} 3 \mathrm{D}= & \mathrm{WB} * \mathrm{PR}+\mathrm{WB} * \mathrm{PS}+\mathrm{WB} * \mathrm{AC}+\mathrm{PR} * \mathrm{PS}+\mathrm{PR} \\
& * \mathrm{AC}+\mathrm{PS} * \mathrm{AC},
\end{aligned}
$$

where $\mathrm{N} 3 \mathrm{D}$ is the number of $3 \mathrm{D}$ plots and the numbers of $\mathrm{WB}, \mathrm{PR}, \mathrm{PS}$, and AC parameters are 6, 6, 3, and 7, respectively.

The effects of the four input parameters and the response output parameter on the surface plots relative to the behaviors of the concrete compressive strength are shown by the $3 \mathrm{D}$ plots, each of which illustrates the effects of two factor parameters on each surface plot of the concrete strength. For example, Figure 1 shows six samples of 3D plots from all 177 experimental graphs with $\mathrm{WB}=0.43, \mathrm{PR}=0, \mathrm{PS}=6.3$, and $\mathrm{AC}=3$, where two parameters are fixed, and two parameters are independent. The compressive strength increases when WB decreases at all values of AC, PR, and PS (Figures 1(a)- 1(c)). In Figures 1(b), 1(d), and 1(f), when AC increases, the compressive strength also increases for all values of WB, PR, and PS. In Figures 1(c), 1(e), and 1(f), decreasing the PS increases the strength at all levels of $\mathrm{AC}, \mathrm{PR}$, and $\mathrm{WB}$. However, the graphs of the $3 \mathrm{D}$ plots are not sufficiently smooth owing to the use of insufficient data. The use of more information can further smoothen the graph. These findings indicate that the ANN model can be used to predict the compressive strength and better clarify the relationships among all the factor parameters.

Furthermore, it was observed that, at the same WB and replacement of GBA, the concrete mixed with the coarser GBA exhibited a lower compressive strength than that of the concrete with the finer GBA. As shown in Figure 1(d), the compressive strength of GBA concrete at early ages (before 28 days) depended on the percent replacement of the GBA. A lower replacement of GBA yielded a higher compressive strength of concrete. This result is similar to that reported in other studies $[9,10]$, in which original and ground BA were used to replace Portland cement. For high fineness GBA, at a later age, the concretes with a higher percent replacement of GBA produced a higher compressive strength than those with lower replacement and the control concretes. Moreover, the results suggested that a higher cementitious material content of GBA concrete corresponded to a higher development rate of compressive strength, when the cementitious material contents were in the range of 244 to $454 \mathrm{~kg} / \mathrm{m}^{3}$, especially at the early ages (before 28 days). These results further indicated that the fineness and percent replacement of GBA are important factors that affect the compressive strength of concrete, and GBA with a high fineness can be used as a pozzolanic material for concrete.

4.2. ANN Model Performance and Equation. The ANN models were developed by using the command line code in the command window of the MATLAB software. A graphical user interface was applied to create $2 \mathrm{D}$ and $3 \mathrm{D}$ plots by using the experimental results and predictive model values in MATLAB. In this study, $83.5 \%$ and $16.5 \%$ of the 
TABLE 5: Range values and numerable parameters of experiment and prediction.

\begin{tabular}{lcccc}
\hline Input and output parameters & Minimum & $\begin{array}{c}\text { Values } \\
\text { Increment }\end{array}$ & Maximum & Numbers \\
& 0.43 & 0.01 & 0.8 & 6 \\
Prediction
\end{tabular}

Experimental results; PR0 PS6.3

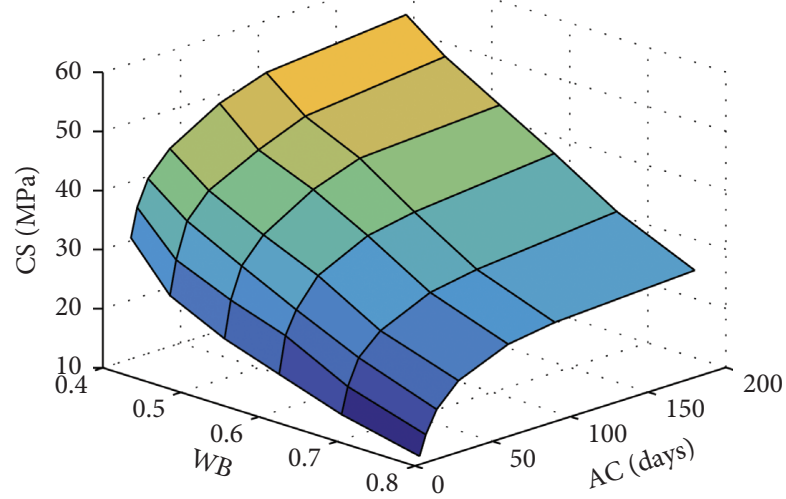

(a)

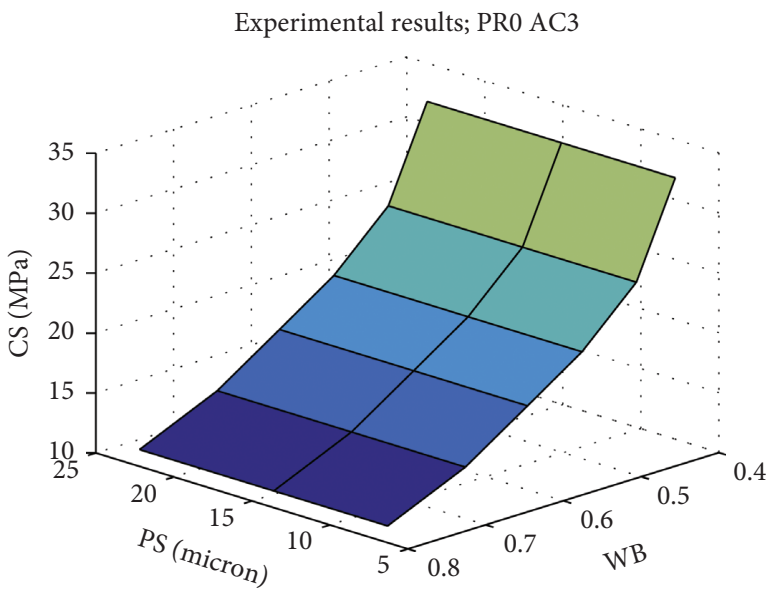

(c)

Experimental results; WB0.43 AC3

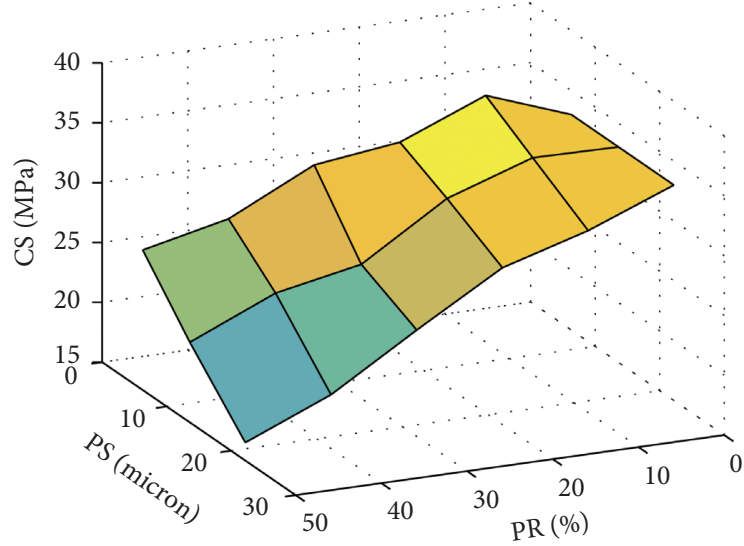

(e)
Experimental results; PS6.3 AC3

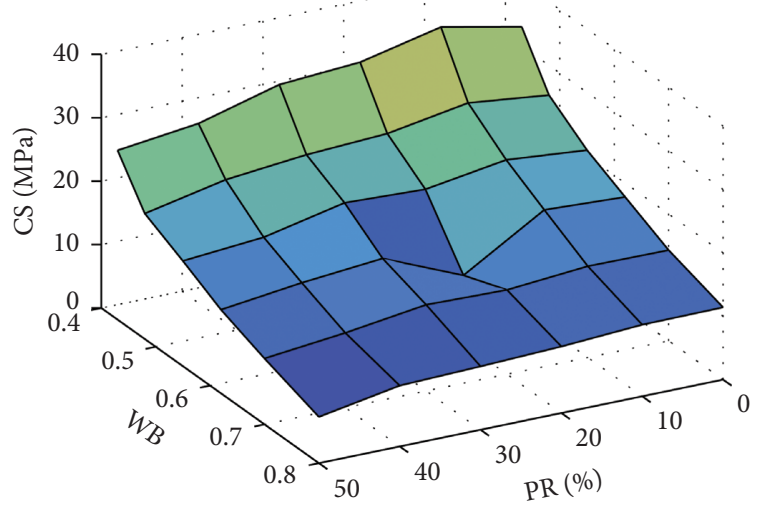

(b)

Experimental results; WB0.43 PS6.3

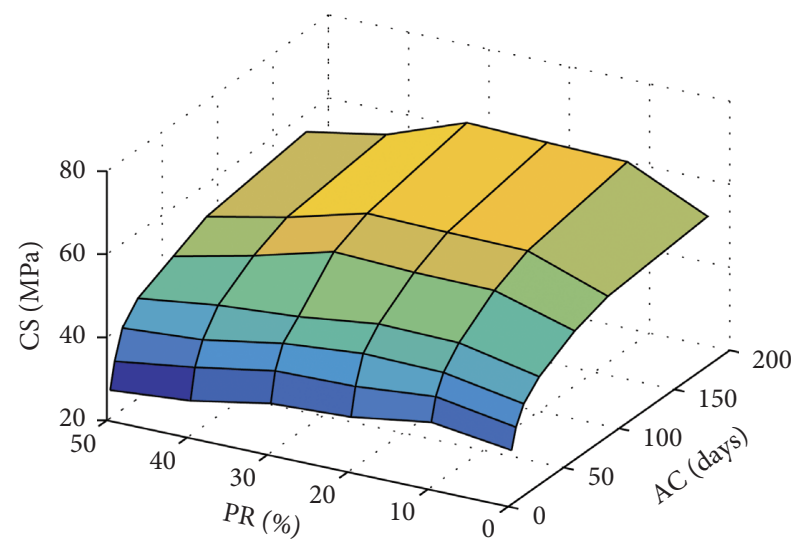

(d)

Experimental results; WB0.43 PR0

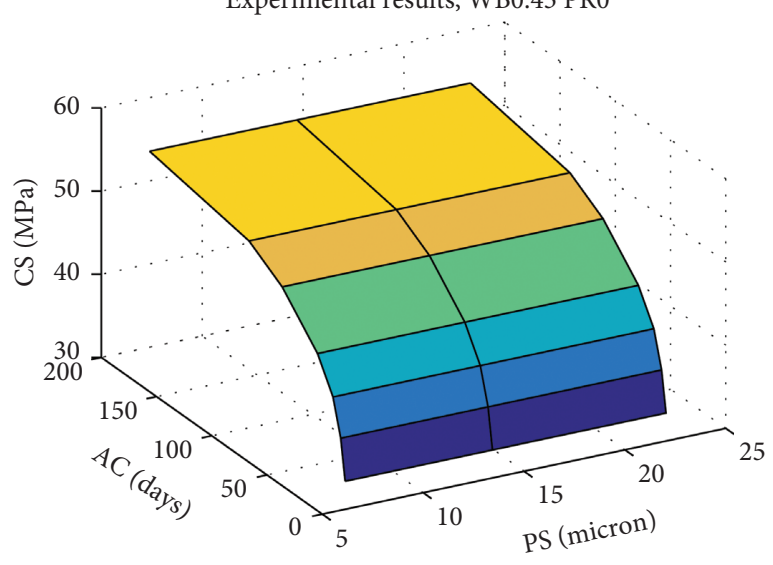

(f)

FIGURE 1: The 3D plots of experimental results with the factor parameters of $\mathrm{WB}=0.43, \mathrm{PR}=0, \mathrm{PS}=6.3$, and $\mathrm{AC}=3$. (a) $\mathrm{PR}=0$ and $\mathrm{PS}=6.3$. (b) $\mathrm{PS}=6.3$ and $\mathrm{AC}=3$. (c) $\mathrm{PR}=0$ and $\mathrm{AC}=3$. (d) $\mathrm{WB}=0.43$ and $\mathrm{PS}=6.3$. (e) $\mathrm{WB}=0.43$ and $\mathrm{AC}=3$. (f) $\mathrm{WB}=0.43$ and $\mathrm{PR}=0$. 
TABLE 6: The parameter format used in the ANN models.

\begin{tabular}{|c|c|c|c|c|c|c|c|c|c|c|c|c|c|c|c|c|c|c|c|}
\hline \multirow{2}{*}{\multicolumn{2}{|c|}{ Parameters }} & \multicolumn{18}{|c|}{ Number } \\
\hline & & 1 & 2 & 3 & 4 & 5 & 6 & 7 & 8 & $\ldots$ & 18 & 19 & 20 & $\ldots$ & 108 & 109 & 110 & $\ldots$ & 756 \\
\hline \multirow{4}{*}{ Input } & WB & 0.8 & 0.8 & 0.8 & 0.8 & 0.8 & 0.8 & 0.8 & 0.8 & $\ldots$ & 0.8 & 0.7 & 0.7 & 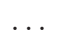 & 0.43 & 0.8 & 0.8 & $\ldots$ & 0.43 \\
\hline & PR & 0 & 10 & 20 & 30 & 40 & 50 & 0 & 10 & . & 50 & 0 & 10 & & 50 & 0 & 10 & $\ldots$ & 50 \\
\hline & PS & 6.3 & 6.3 & 6.3 & 6.3 & 6.3 & 6.3 & 13.6 & 13.6 & $\ldots$ & 22.2 & 6.3 & 6.3 & $\ldots$ & 22.2 & 6.3 & 6.3 & $\ldots$ & 22.2 \\
\hline & $\mathrm{AC}$ & 3 & 3 & 3 & 3 & 3 & 3 & 3 & 3 & $\ldots$ & 3 & 3 & 3 & $\ldots$ & 3 & 7 & 7 & $\ldots$ & 180 \\
\hline Output & CS & 11.4 & 11.3 & 10.5 & 10 & 9.6 & 7.3 & 11.4 & 9.9 & $\ldots$ & 4.6 & 14.3 & 14.4 & $\ldots$ & 16.5 & 14.7 & 14.9 & $\ldots$ & 44.2 \\
\hline
\end{tabular}

experimental dataset were randomly selected and used to train (631 sets of experimental data) and test (125 sets of experimental data) the model, respectively. The formats of the variables were run by the ANN model and are presented in Tables 6 and 7 for the input and output datasets, respectively.

The optimal ANN model was determined by investigating the model performance. The results showed that the optimal ANN model had two hidden layers with six neurons in the first hidden layer and one neuron in the second hidden layer. The optimal ANN model was used in the following manner. First, the high-accuracy predictive model was developed by considering both training and testing datasets with statistical values of $R^{2}$ higher than of 0.99 . Second, an explicit model equation was established, as reported in (9)-(11). Finally, the reliable compressive strength behavior was validated by performing the sensitivity analysis using two-dimensional (2D) and three-dimensional (3D) plots to compare the experimental and predictive results. In addition, all the ANN model architectures exhibited $R^{2}$ values higher than 0.94 . The number of hidden layers is not related to $R^{2}$. Although the ANN model provided a high accuracy, the plotted graphs were not consistent with the concrete behavior. Therefore, when choosing the ANN model architecture, the behavior of concrete must be considered. Figure 2 shows a comparison of the $2 \mathrm{D}$ plots of the experimental results and predictive results of the ANN model architectures with one hidden layer and $R^{2}$ higher than of 0.99. Figure 2(b) (one hidden layer with six neurons) shows that the trend lines more closely match the experimental lines than those shown in Figure 2(a) (one hidden layer with five neurons) and Figure 2(c) (one hidden layer with 14 neurons). Therefore, the ANN model architecture with one hidden layer with six neurons is the best model for one hidden layer. Figure 3 shows a comparison of the 2D plots of the experimental results and predictive results of the ANN model architectures with two hidden layers and $R^{2}$ higher than 0.99. In Figure 3(b) (two hidden layers with six neurons in the first hidden layers and one neuron in the second hidden layers), the trend lines more closely match the experimental lines than those in Figure 3(a) (two hidden layers with six neurons in the first hidden layer and zero neurons in the second hidden layer) and Figure 3(c) (two hidden layer with six neurons in the first hidden layer and two neurons in the second hidden layer). Therefore, the ANN model architecture with two hidden layers with six neurons in the first hidden layer and one neuron in the second hidden layer is the optimal ANN model, which is used in this study.

The parameter settings in the optimal ANN models are presented in Table 8, and the model architecture is shown in Figure 4. The optimal ANN model exhibits an acceptable performance and high accuracy because the absolute fraction of variance $\left(R^{2}\right)$ is higher than 0.99 , and the RMSE and MAPE are lower than 3.4569 for both the training and testing datasets, as shown in Table 9. The weight matrices and bias vectors of the network were extracted to adjust the parameters, as presented in Table 10. Therefore, the explicit ANN-modeled formulation of the compressive strength of GBA concrete can be mathematically expressed as follows:

$$
\begin{aligned}
& X_{1}=(2.2520 * \mathrm{WB})-(0.3981 * \mathrm{PR})+(0.1426 * \mathrm{PS})-(0.0140 * \mathrm{AC})-(3.4309) \\
& X_{2}=-(1.3586 * \mathrm{WB})-(0.0135 * \mathrm{PR})-(0.0106 * \mathrm{PS})+(0.0006 * \mathrm{AC})-(0.6791) \\
& \vdots \\
& X_{6}=-(0.3361 * \mathrm{WB})+(0.0009 * \mathrm{PR})+(0.0017 * \mathrm{PS})-(0.1433 * \mathrm{AC})-(2.9575)
\end{aligned}
$$

where $X_{1}, X_{2}, \ldots, X_{6}$ denote the summations of the weighted inputs with the addition of the bias values of the first hidden layer. Next, the log-sigmoid activation function in the first hidden layer is as follows: 


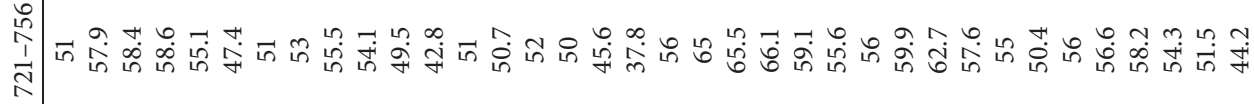

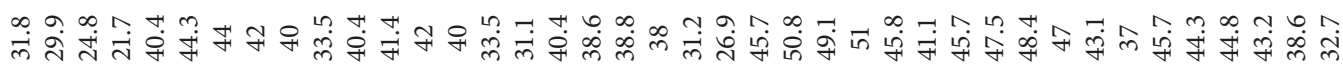

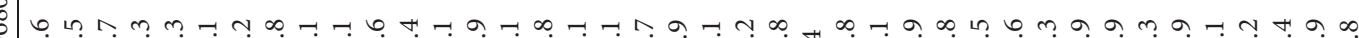

我

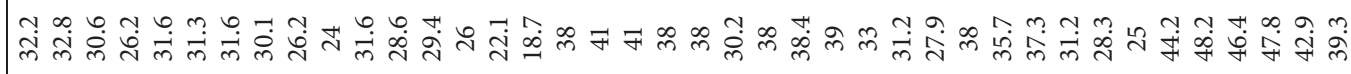

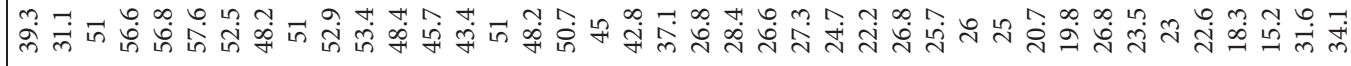

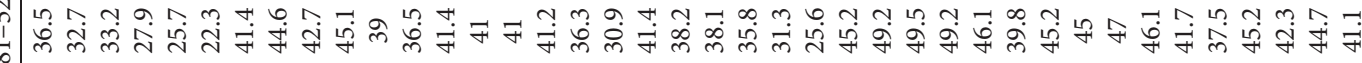

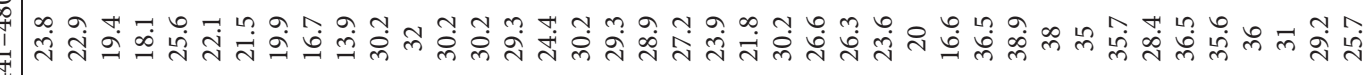

붕 F

萑

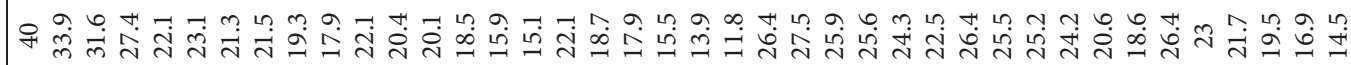

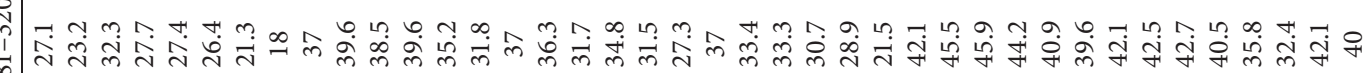

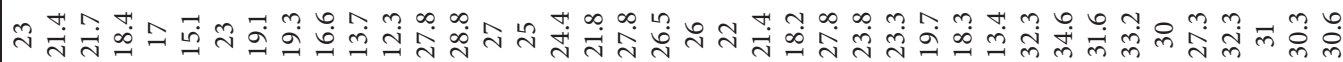

ma

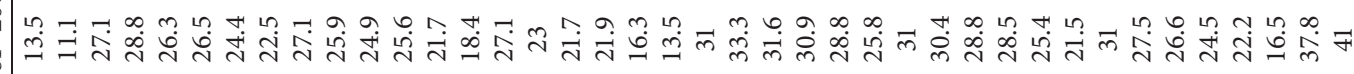

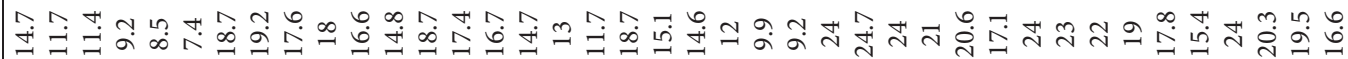

売

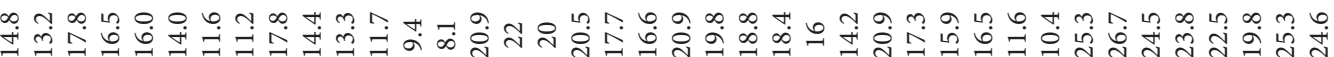

I है 


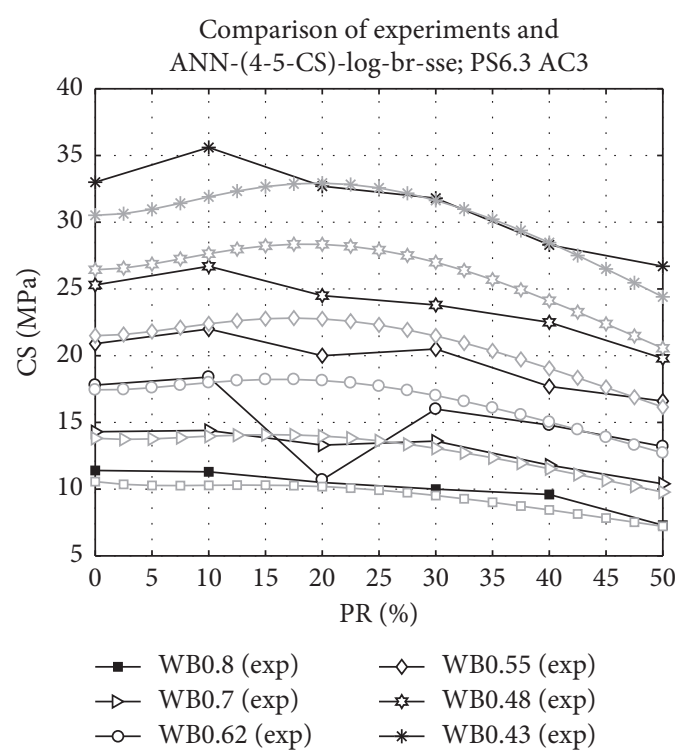

(a)

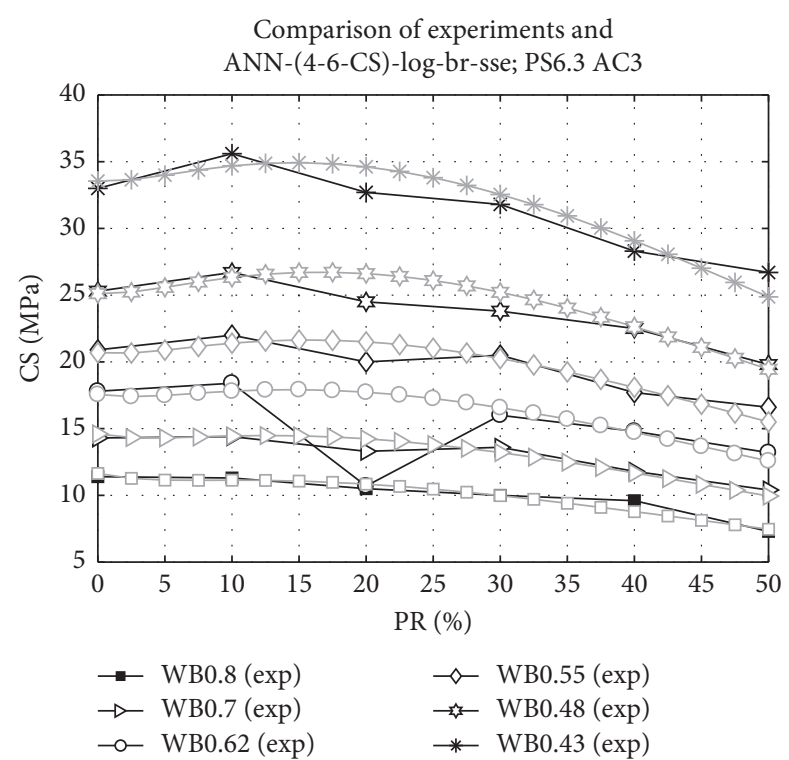

(b)

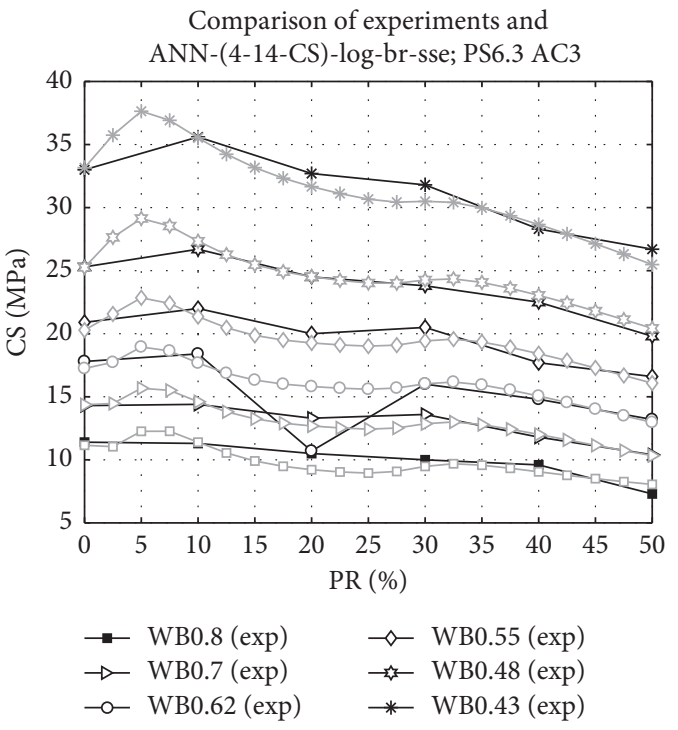

(c)

FIGURE 2: Comparison between the 2D plots of experimental results and predictive results of the ANN model architectures with one hidden layer. (a) One hidden layer with 5 neurons. (b) One hidden layer with 6 neurons. (c) One hidden layer with 14 neurons.

$$
\begin{gathered}
H_{1}=-\left(0.1391 *\left(\frac{1}{\left(1+e^{X_{1}}\right)}\right)\right)-\left(20.4516 *\left(\frac{1}{\left(1+e^{X_{2}}\right)}\right)\right)-\left(5.2081 *\left(\frac{1}{\left(1+e^{X_{3}}\right)}\right)\right)+ \\
\left(0.2904 *\left(\frac{1}{\left(1+e^{X_{4}}\right)}\right)\right)+\left(11.8122 *\left(\frac{1}{\left(1+e^{X_{5}}\right)}\right)\right)+\left(10.8229 *\left(\frac{1}{\left(1+e^{X_{6}}\right)}\right)\right)+1.9325 .
\end{gathered}
$$

Finally, the tan-sigmoid activation function in the second hidden layer and the sum of the output layer is

$$
\mathrm{CS}=-\left(66.2254 *\left(\frac{2}{\left(1+e^{-2\left(H_{1}\right)}\right)}-1\right)\right)+63.2786
$$

An ANN predicted model was thus developed to establish the reliable behavior and accurate estimation of the compressive strength of GBA concrete. The results indicated that the optimal ANN model, which has two hidden layers with six neurons in the first hidden layer and one neuron in the second hidden layer, is represented by four factor parameters (WB, PR, PS, and AC). In addition, the log-sigmoid 


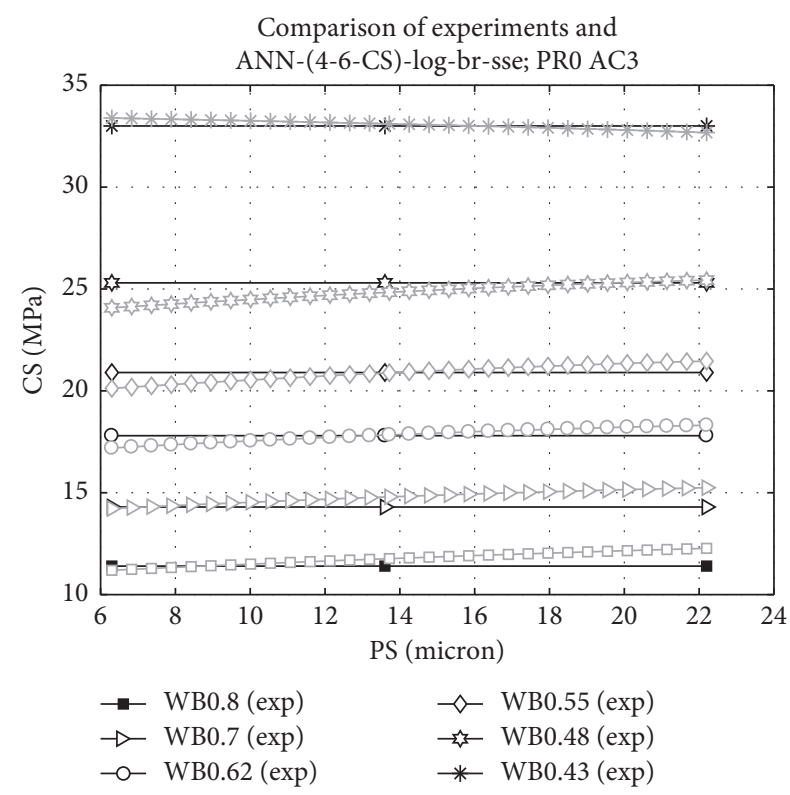

(a)

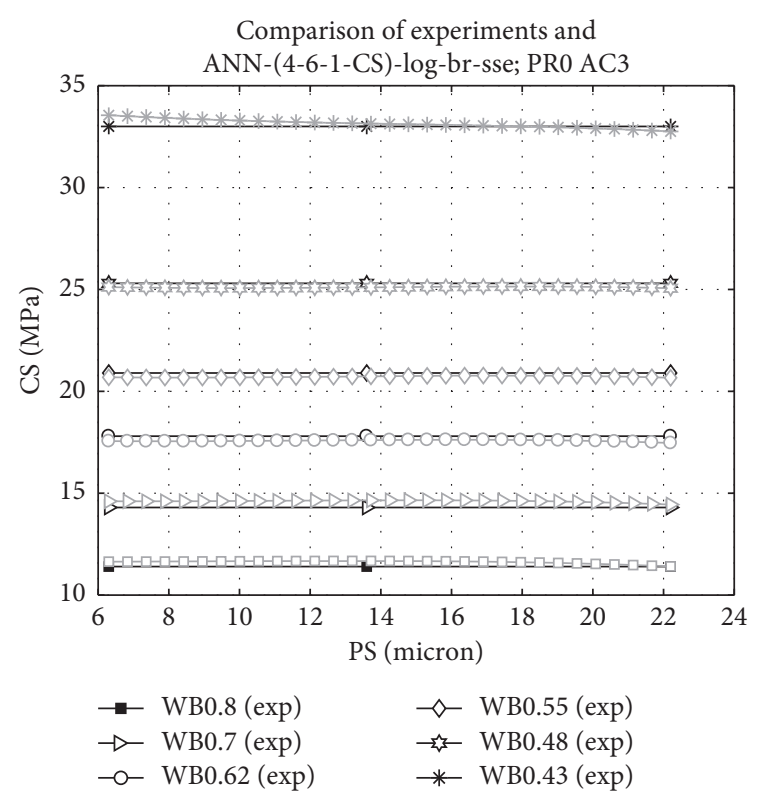

(b)

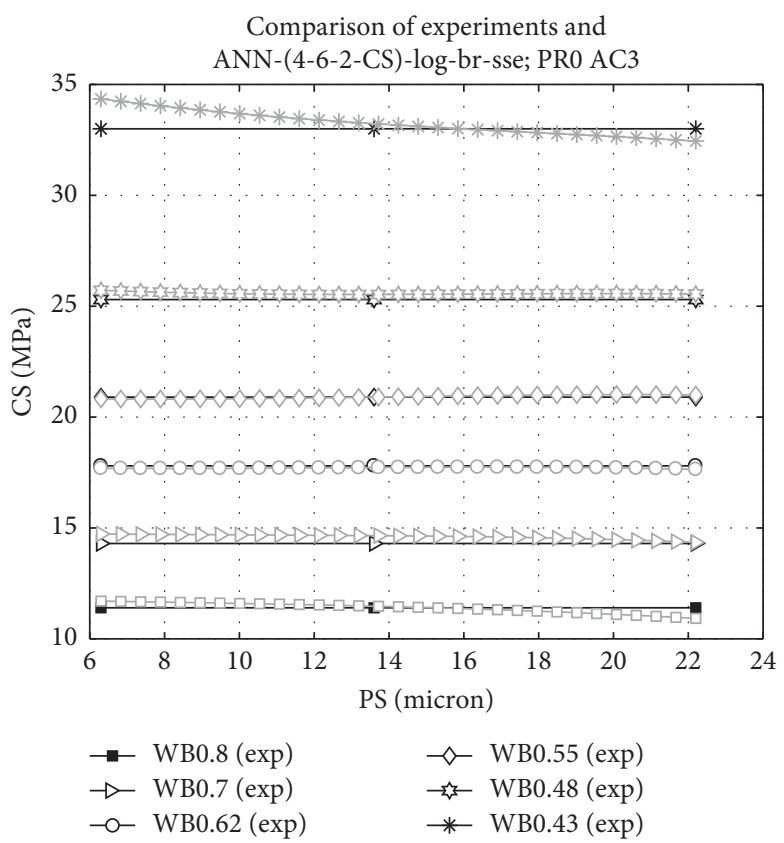

(c)

FIGURE 3: Comparison between the 2D plots of experimental results and predictive results of the ANN model architectures with two hidden layers. (a) Two hidden layers with 6 neurons in the first hidden layer and 0 neuron in the second hidden layer. (b) Two hidden layers with 6 neurons in the first hidden layer and 1 neuron in the second hidden layer. (c) Two hidden layers with 6 neurons in the first hidden layer and 2 neurons in the second hidden layer.

and tan-sigmoid activation functions were employed in the first and second hidden layers, respectively. The BR was used as the learning algorithm, and the sum square error was used to evaluate the network performance. A high-accuracy predictive model with acceptable error is obtained, with the statistical values of $R^{2}$, MAPE, and RMSE being 0.9969, 2.4586 , and 3.339, respectively, for the training dataset and $0.9968,2.6417$, and 3.4569 , respectively, for the testing dataset.
4.3. Sensitivity Analysis. The response surface method is among the most widely used approaches for concrete mixture design optimization [21-25] owing to its simplicity in illustrating the response-related equations to analyze the relationship between the required factors and the required response by using $3 \mathrm{D}$ plots. In addition, a few studies $[15,16]$ pertaining to the field of concrete property predictive models popularized the use of the RMS to represent the reliable behavior pertaining to the concrete property in input-output 
TABLE 8: The parameter setting used in the optimal ANN models.

\begin{tabular}{lc}
\hline Parameter setting & Best model \\
\hline Number of input layer units & 4 \\
Number of first hidden layer units & 6 \\
Number of second hidden layer units & 1 \\
Number of output layer units & 1 \\
Number of epochs & 5,500 \\
Training algorithm & BR \\
Activation function in first hidden layer & Log-sigmoid \\
Activation function in second hidden layer & Tan-sigmoid \\
Activation function in output layer & Purelin \\
Network's performance & sse \\
\hline
\end{tabular}

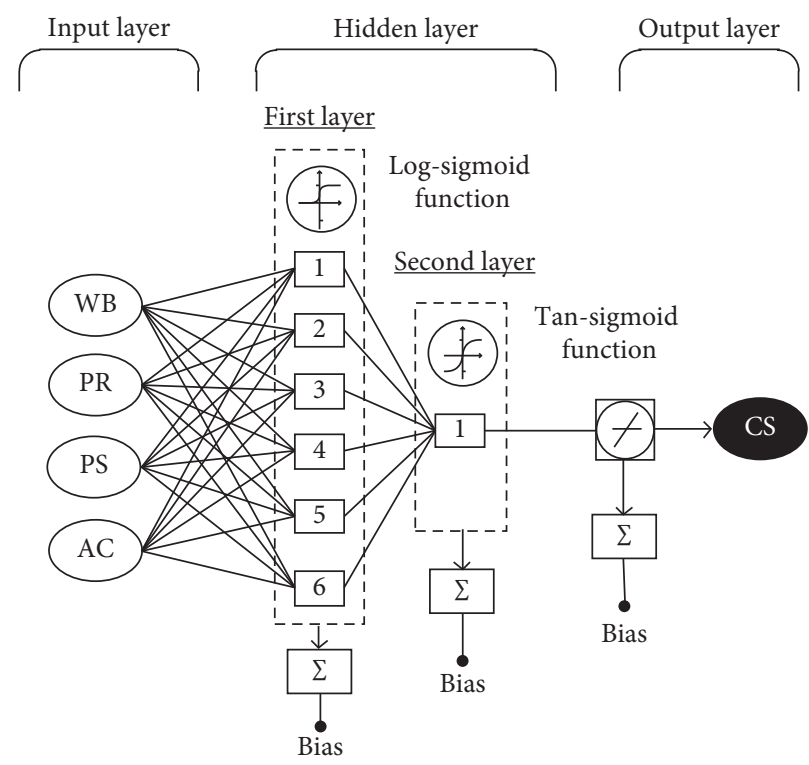

Figure 4: The optimal ANN architecture.

TABLE 9: The optimal ANN model performance measure.

\begin{tabular}{lccccc}
\hline \multirow{2}{*}{ Model } & \multicolumn{3}{c}{ Training data } & \multicolumn{3}{c}{ Testing data } \\
& $R^{2}$ & MAPE & RMSE & $R^{2}$ & MAPE \\
\hline The optimal ANN & 0.9969 & 2.4586 & 3.339 & 0.9968 & 2.6417 \\
\hline
\end{tabular}

predictive relationships. Although [26] discussed that the concrete and microstructure-property relationships are at the heart of modern material science and the analytical methods of material science can model and predict the microstructurally stable behavior, homogeneous materials do not appear to follow this trend in the case of concrete structures. Such a case also pertains to the reliable compressive strength relationship of the GBA concrete behavior. Therefore, the $2 \mathrm{D}$ and $3 \mathrm{D}$ plots from the sensitivity analysis were used to illustrate the reliable relative behavior of the measured values and predicted values for comparison. The $3 \mathrm{D}$ plots of the ANN-based prediction results show the response-related equations of the surface plot of the ANN model. The $2 \mathrm{D}$ plots show the relationship of a factor variable and a response variable in the form of the trend lines of the measured and predicted values, which involve a side view of the $3 \mathrm{D}$ plots and can clearly illustrate the reliable compressive strength behavior of the predictive model.

Table 5 presents the value of each input parameter at various levels in the model and the output concrete compressive strength. The input datasets of the predictive model were as follows: $\mathrm{WB}=[0.43: 0.01: 0.80], \mathrm{PR}=[0: 2: 50]$, $\mathrm{PS}=[6.3: 0.3: 22.2]$, and $\mathrm{AC}=[3: 3: 180]$ in the form of $[m:$ $\mathrm{i}: n]$, where $m, i$, and $n$ denote the initial, incremental, and final values of the input variable, respectively. In total, $3,201,120$ sets of input variable data were calculated from 38, 26,54 , and 60 variables of WB, PR, PS, and AC, respectively. In addition, the sensitivity analysis findings to compare the measured and predicted values were represented in the form of $2 \mathrm{D}$ and $3 \mathrm{D}$ plots.

Figure 5 shows six samples of 3D plots from all 177 predictive graphs of the optimal ANN models with identical 


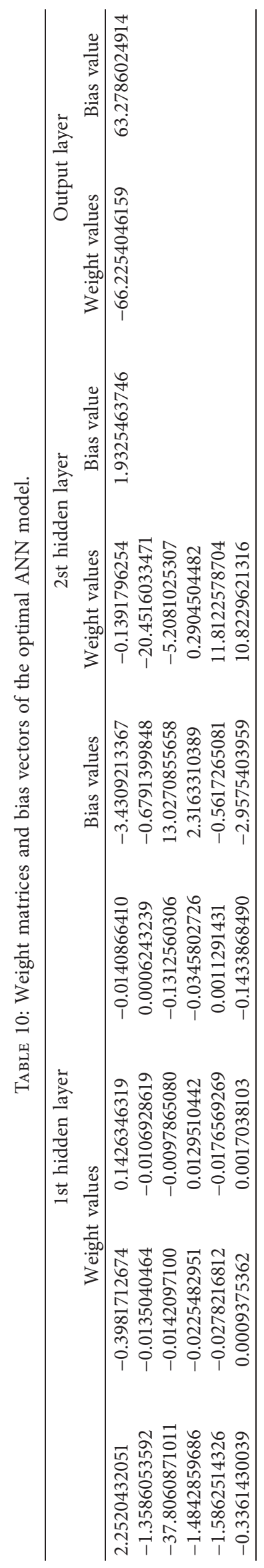




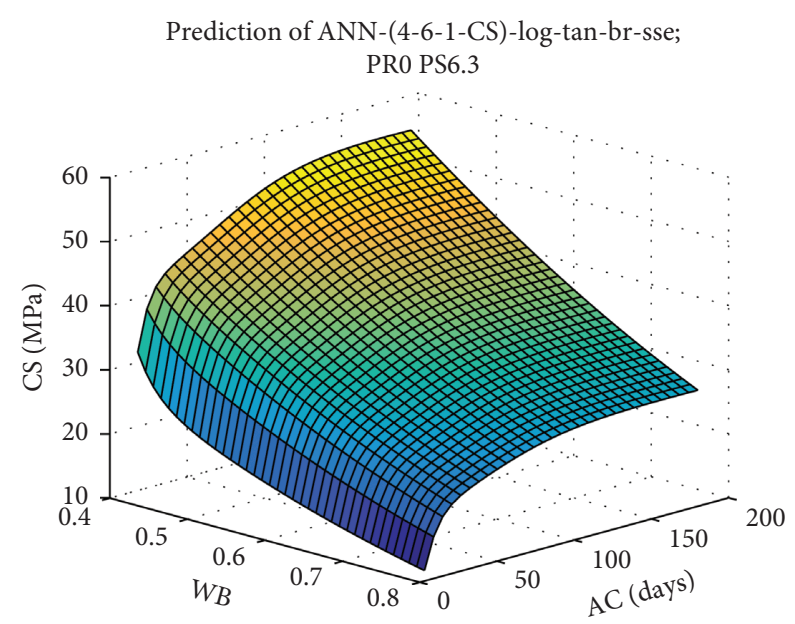

(a)

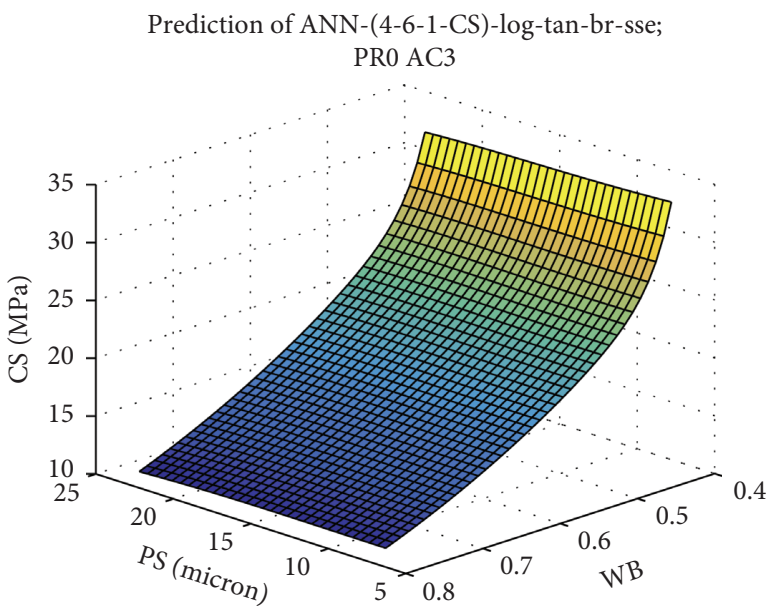

(c)

Prediction of ANN-(4-6-1-CS)-log-tan-br-sse; AC3 WB0.43

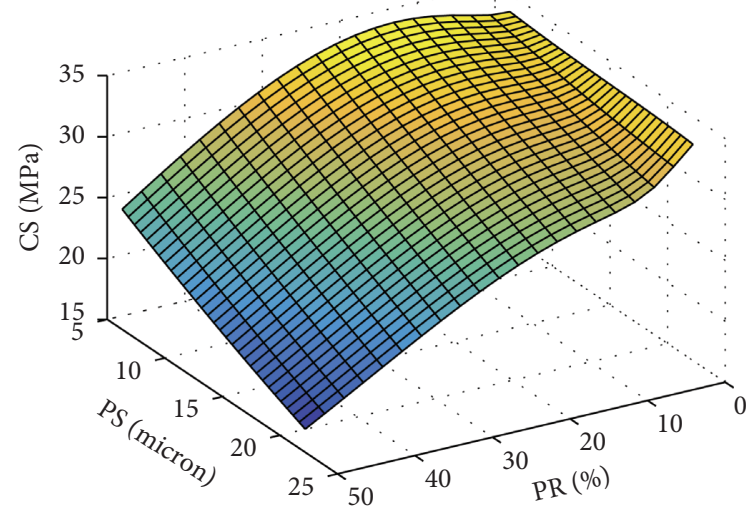

(e)

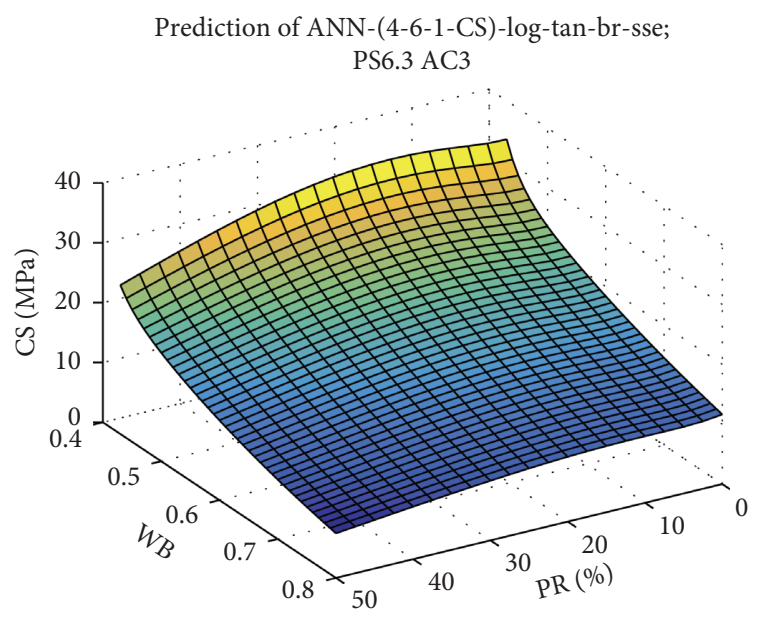

(b)

Prediction of ANN-(4-6-1-CS)-log-tan-br-sse; PS6.3 WB0.43

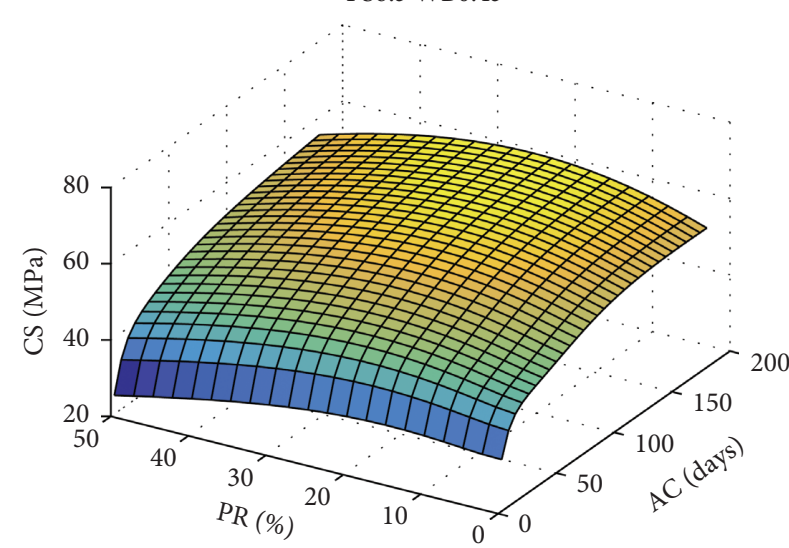

(d)

Prediction of ANN-(4-6-1-CS)-log-tan-br-sse; WB0.43 PR0

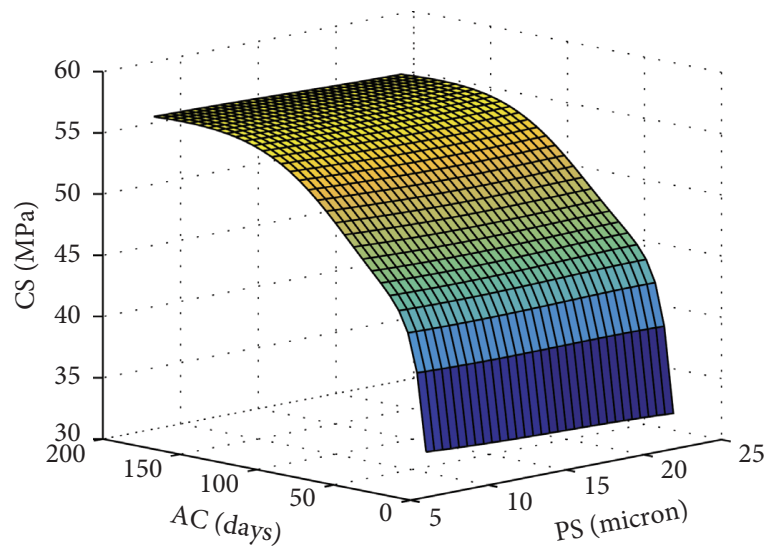

(f)

FIGURE 5: The 3D plots of predictive results of the optimal $\mathrm{ANN}$ models with the factor parameter of $\mathrm{WB}=0.43, \mathrm{PR}=0, \mathrm{PS}=6.3$, and $\mathrm{AC}=3$. (a) $\mathrm{PR}=0$ and $\mathrm{PS}=6.3$. (b) $\mathrm{PS}=6.3$ and $\mathrm{AC}=3$. (c) $\mathrm{PR}=0$ and $\mathrm{AC}=3$. (d) $\mathrm{WB}=0.43$ and $\mathrm{PS}=6.3$. (e) $\mathrm{WB}=0.43$ and $\mathrm{AC}=3$. (f) $\mathrm{WB}=0.43$ and $\mathrm{PR}=0$.

parameters as shown in Figure 1. The relationship of the parameters is clearer, and the graph has smoother characteristics. All the $3 \mathrm{D}$ predictive plots shown in Figure 5 correspond to the surface plots of the experimental results in Figure 1, which have identical parameters. Furthermore, the $2 \mathrm{D}$ plots guarantee the reliable predictive behavior 

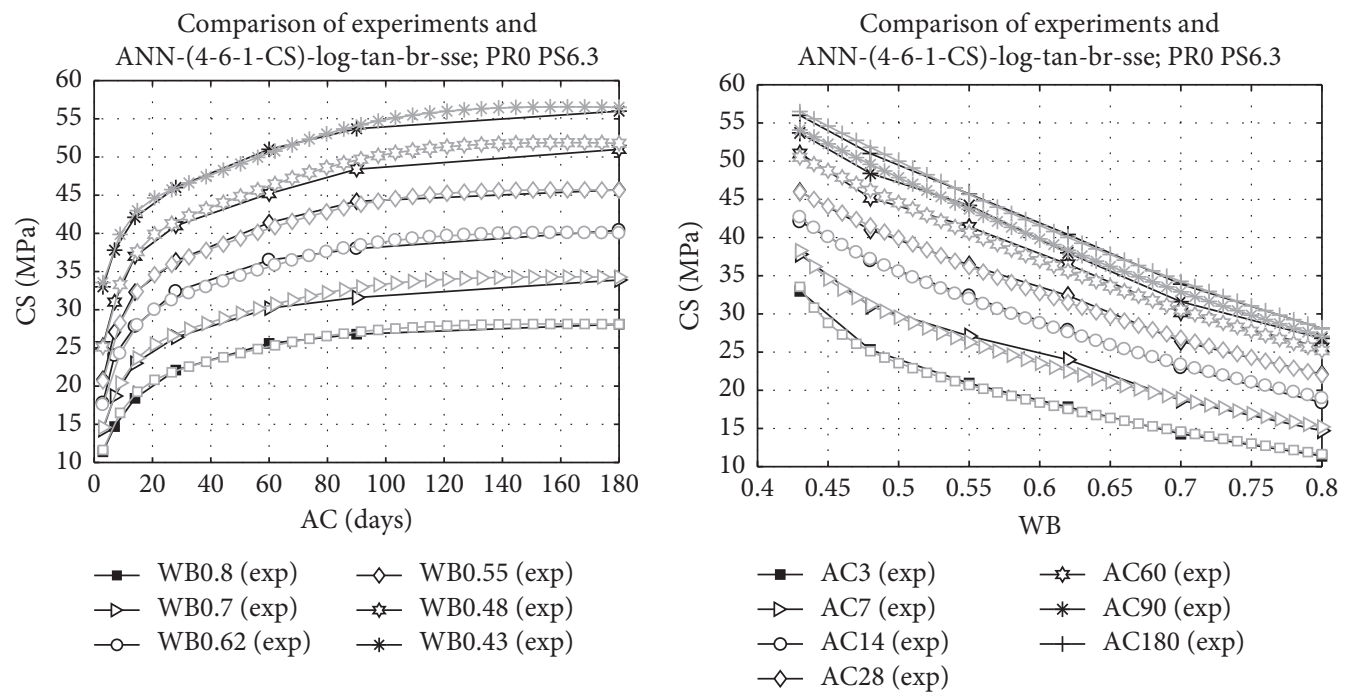

(a)

(b)

Comparison of experiments and

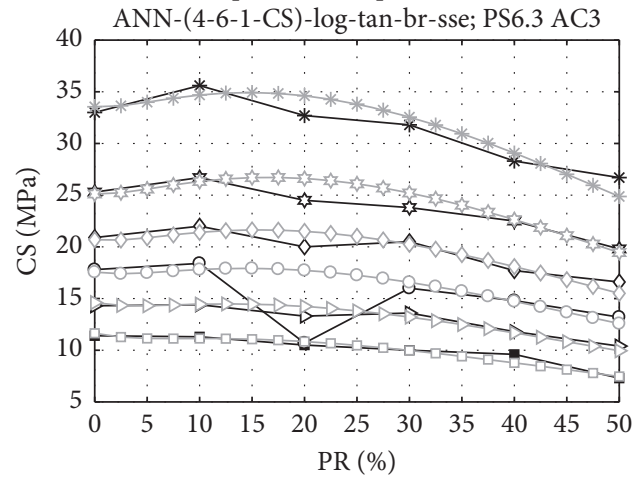

Comparison of experiments and

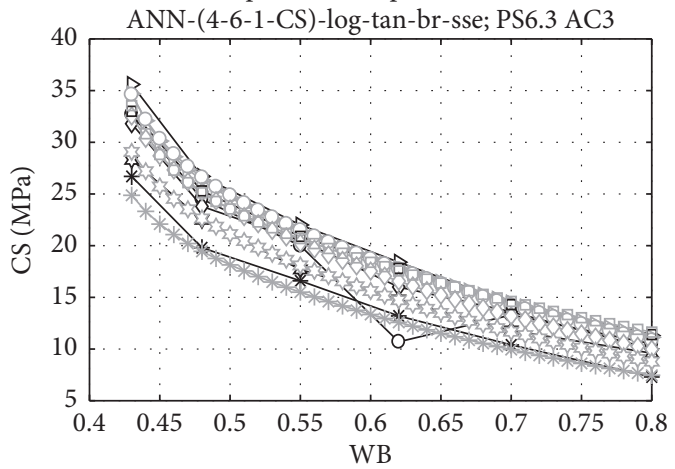

$\rightarrow \mathrm{WB} 0.8(\exp ) \quad \neg-\mathrm{WB} 0.55(\exp )$

$\rightarrow$ WB0.7 (exp) $\rightarrow$ WB0.48 (exp)

$\multimap$ WB0.62 (exp) * WB0.43 (exp)

(c)

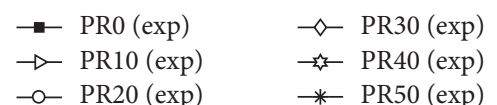

(d)

Comparison of experiments and ANN-(4-6-1-CS)-log-tan-br-sse; PR0 AC3

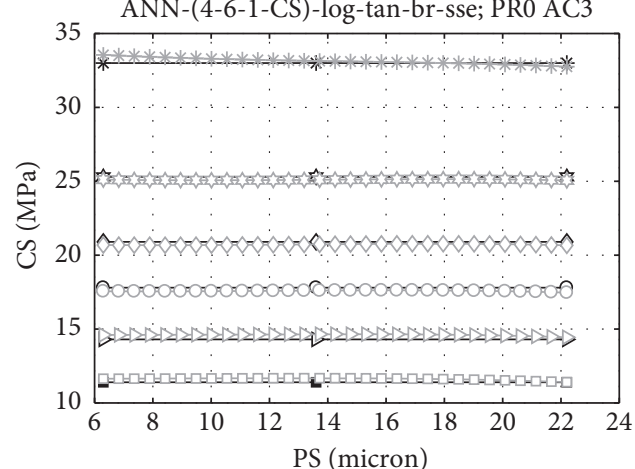

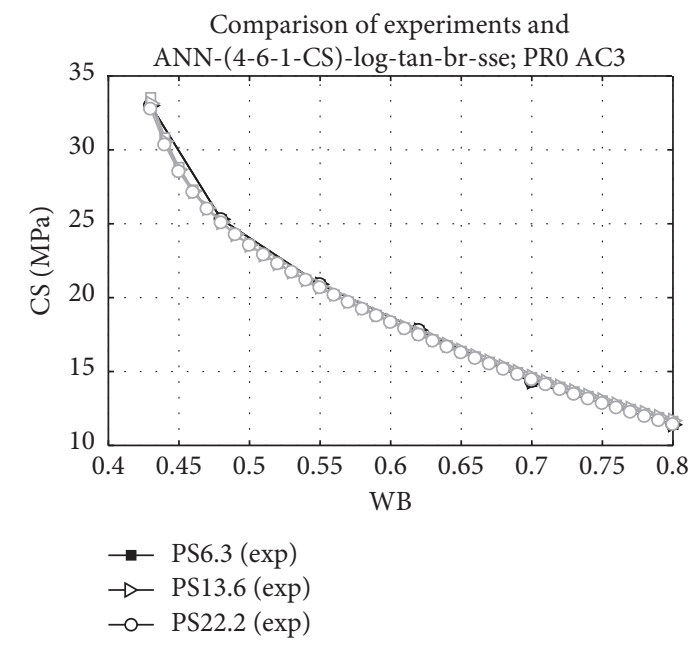

(e)

FIgURE 6: Continued. 


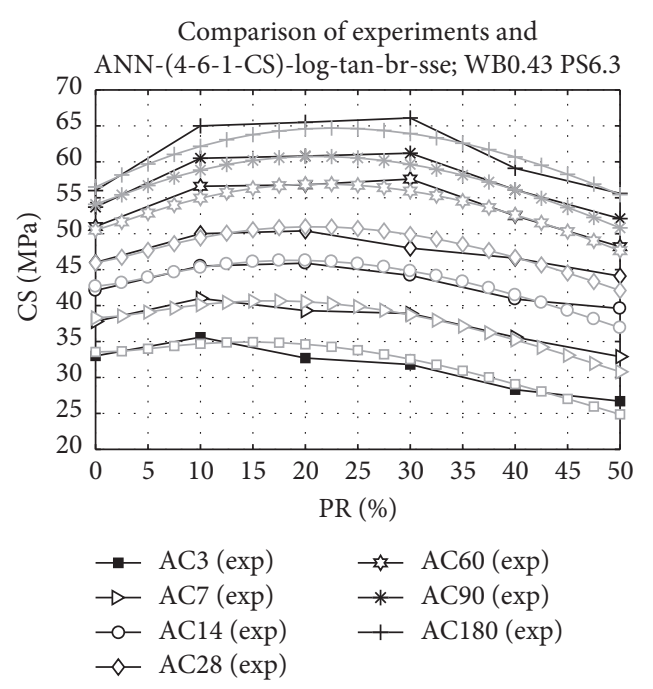

(g)

Comparison of experiments and

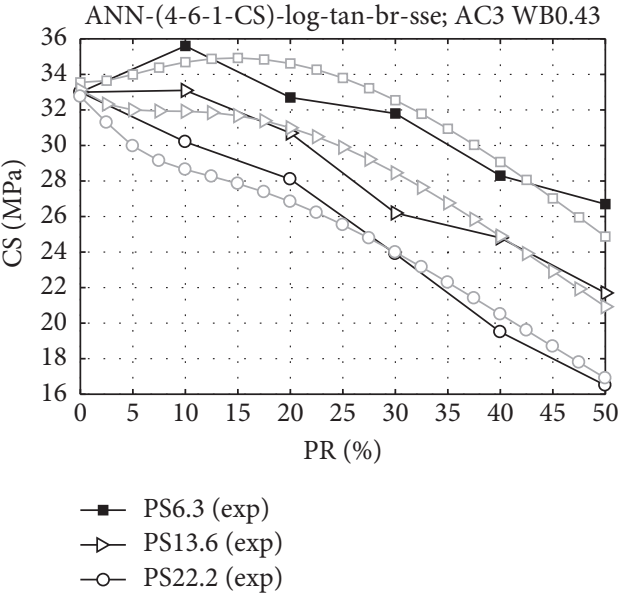

(i)

Comparison of experiments and

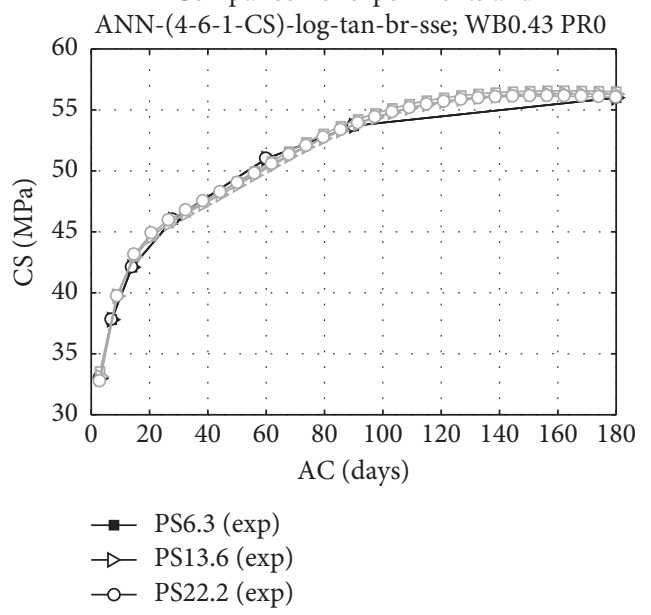

(k)

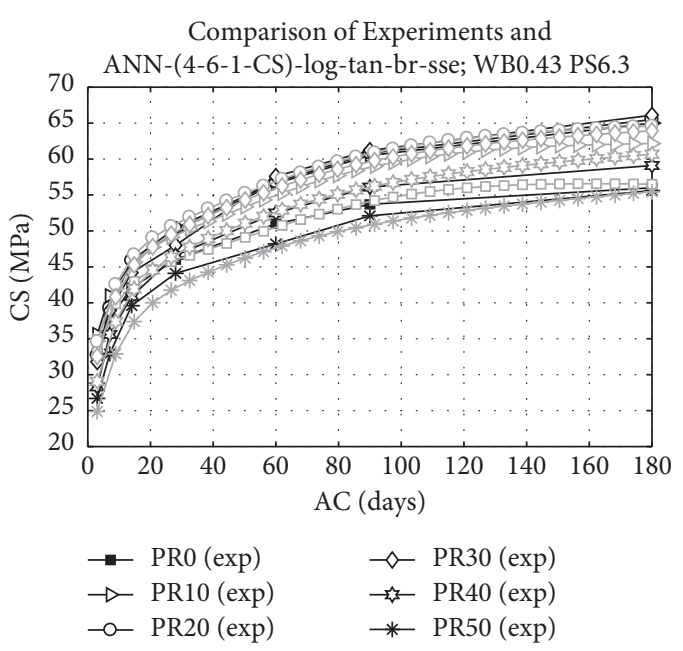

(h)

Comparison of experiments and ANN-(4-6-1-CS)-log-tan-br-sse; AC3 WB0.43

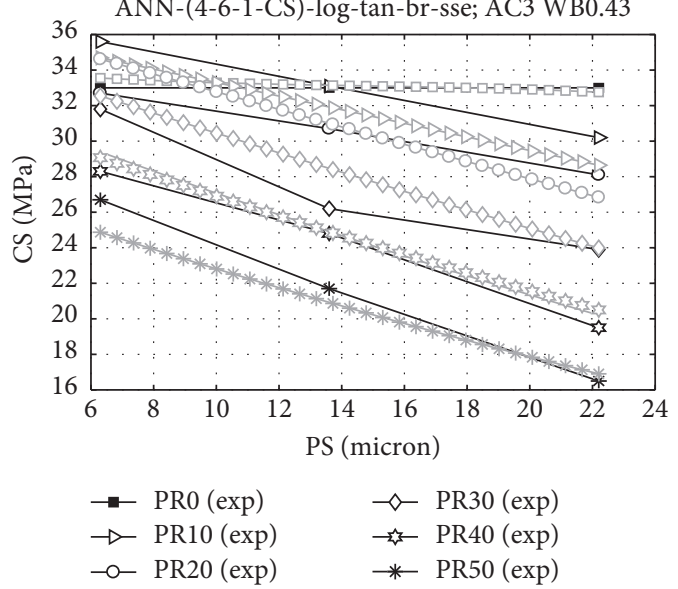

(j)

Comparison of experiments and ANN-(4-6-1-CS)-log-tan-br-sse; WB0.43 PR0

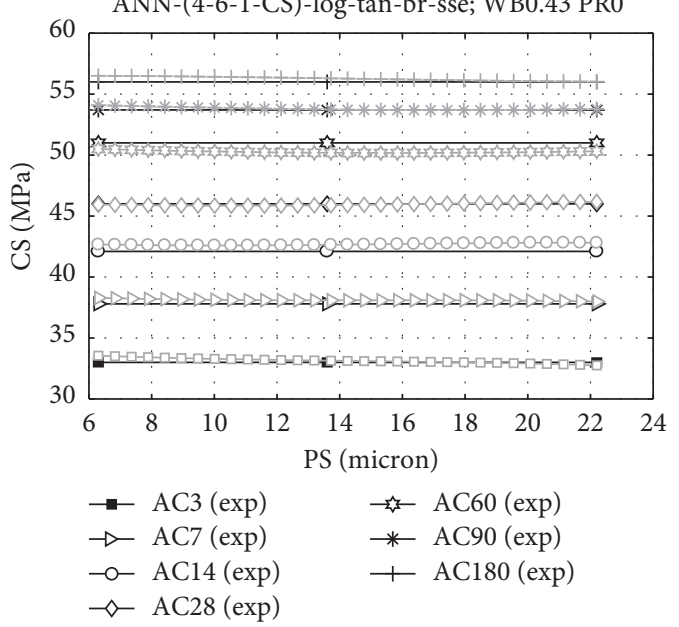

(l)

FIgURE 6: The 2D plots of comparison between experimental results and predictive results of the optimal ANN models with the factor parameter of $\mathrm{WB}=0.43, \mathrm{PR}=0, \mathrm{PS}=6.3$, and $\mathrm{AC}=3$. 
concerning the side view of the $3 \mathrm{D}$ plots, as shown by the samples shown in Figure 6. The predictive values of the optimal ANN model are remarkably close to the experimental results, which indicate a strong correlation between the predictive and measured values. In addition, it is demonstrated that the optimal ANN model can provide reliable intelligence and accurate analysis because the predictive results are better correlated with the plotting surface of the $3 \mathrm{D}$ plots and trend lines of the $2 \mathrm{D}$ plots than the experimental results, as shown in Figures 1(b), 5(b), 6(c), and $6(\mathrm{~d})$. However, the remaining $2 \mathrm{D}$ and $3 \mathrm{D}$ plots can be validated by using the explicit equation of the optimal ANN model by creating the $2 \mathrm{D}$ and $3 \mathrm{D}$ plots with this equation. Moreover, it can be observed that, at the same WB ratio and the same percent replacement, concrete mixed with coarser GBA produces a compressive strength lower than that of concrete with the finer GBA. The compressive strengths of the GBA concretes at the early ages (before 28 days) depend on the percent replacement. A lower percent replacement corresponds to a higher compressive strength of concrete than that for the case with the higher percent replacement. This result was similar to the findings of existing studies $[27,28]$.

\section{Conclusions}

The following conclusions were drawn from the abovementioned investigation:

(1) The compressive strengths of GBA concretes at the early ages depend on the percent replacement. A lower percent replacement of GBA yields a higher compressive strength of concrete compared to that in the case with a higher percent replacement. At the latter ages, the compressive strength depends on the fineness of the GBA; in particular, concrete mixed with coarser ground bottom ash yields a compressive strength lower than that of the concrete with the finer GBA.

(2) The WB, PR of GBA, PS of GBA, and AC are the major parameters affecting the strength development of concrete, and a GBA with a high fineness can be used as a good pozzolanic material.

(3) The optimal ANN model has an architecture with two hidden layers with six neurons in the first hidden layer and one neuron in the second hidden layer. The log-sigmoid and tan-sigmoid activation functions are used in the first and second hidden layers, respectively, BR is used as the learning algorithm, and the SSE is used to evaluate the network performance. The high-accuracy predictive model has the statistical values of $R^{2}$, MAPE, and RMSE as 0.9969, 2.4586, and 3.339, respectively, for the training dataset and $0.9968,2.6417$, and 3.4569 , respectively, for the testing dataset.

(4) The results conclusively prove that the proposed ANN-based-explicit equations can reasonably generalize the actual output and the target output. The
$2 \mathrm{D}$ and $3 \mathrm{D}$ plots of the compressive strength behavior from the optimal ANN model closely matched and correspondingly followed the trend lines and surface plots of the experimental results.

\section{Data Availability}

The data used to support the findings of this study are included within the article. Any additional data related to the paper may be requested from the corresponding author.

\section{Conflicts of Interest}

The authors declare that there are no conflicts of interest regarding the publication of this paper.

\section{Acknowledgments}

This research received financial support from Faculty of Engineering, Mahasarakham University. In addition, the authors thank Mr. Anon Chuachun from the Concrete Research Laboratory (CRL) for his valuable assistance in the exhaustive experimental work.

\section{References}

[1] I. Topcu and M. Saridemir, "Prediction of compressive strength of concrete containing fly ash using artificial neural networks and fuzzy logic," Computational Materials Science, vol. 41, no. 3, pp. 305-311, 2018.

[2] M. Saridemir, "Prediction of compressive strength of concretes containing metakaolin and silica fume by artificial neural networks," Advances in Engineering Software, vol. 40, no. 5, pp. 350-355, 2009.

[3] C. Bilim, C. D. Atiş, H. Tanyildizi, and O. Karahan, "Predicting the compressive strength of ground granulated blast furnace slag concrete using artificial neural network," $A d$ vances in Engineering Software, vol. 40, no. 5, pp. 334-340, 2009.

[4] S. Inthata, W. Kowtanapanich, and R. Cheerarot, "Prediction of chloride permeability of concretes containing ground pozzolans by artificial neural networks," Materials and Structures, vol. 46, no. 10, pp. 1707-1721, 2013.

[5] N. Ghafoori and Y. Cai, "Laboratory-made roller compacted concretes containing dry bottom ash:part I mechanical properties," ACI Materials Journal, vol. 95, no. 2, pp. 121-130, 1998.

[6] N. Ghafoori and Y. Cai, "Laboratory-made roller compacted concretes containing dry bottom ash: part II long term durability," ACI Materials Journal, vol. 95, no. 3, pp. 244-251, 1998.

[7] N. Ghafoori and J. Bucholc, "Investigation of lignite-based bottom ash for structural concrete," Journal of Materials in Civil Engineering, vol. 8, no. 3, pp. 128-137, 1996.

[8] N. Ghafoori and J. Bucholc, "Properties of high-calcium dry bottom ash concrete," ACI Materials Journal, vol. 94, no. 5, pp. 90-101, 1997.

[9] C. Jaturapitakkul and R. Cheerarot, "Development of bottom ash as pozzolanic material," Journal of Materials in Civil Engineering, vol. 15, no. 1, pp. 48-53, 2003.

[10] M. Cheriaf, J. C. Rocha, and J. Péra, "Pozzolanic properties of pulverized coal combustion bottom ash," Cement and Concrete Research, vol. 29, no. 9, pp. 1387-1391, 1999. 
[11] American Society for Testing and Materials (ASTM) C 61812a, Standard Specification for Coal Fly Ash and Raw or Calcined Natural Pozzolan for Use Mineral Admixture in Portland Cement Concrete, ASTM, West Conshohocken, PA, USA, 2012.

[12] American Society for Testing and Materials (ASTM) C39/ C39M-12a, Standard Test Method for Compressive Strength of Cylindrical Concrete Specimens, ASTM, West Conshohocken, PA, USA, 2012.

[13] M. Negnevitsky, Artificial Intelligence: A Guide to Intelligent Systems, Pearson Education Limited, London, UK, 1st edition, 2002.

[14] L. H. Tsoukalas and R. E. Uhrig, Fuzzy and Neural Approaches in Engineering, John Wiley \& Sons, Toronto, Canada, 1997.

[15] S. Akkurt, S. Ozdemir, G. Tayfur, and B. Akyol, "The use of GA-ANNs in the modelling of compressive strength of cement mortar," Cement and Concrete Research, vol. 33, no. 7, pp. 973-979, 2003.

[16] S. C. Paul, B. Panda, and A. Garg, "A novel approach in modelling of concrete made with recycled aggregates," Measurement, vol. 115, pp. 64-72, 2018.

[17] M. A. DeRousseau, J. R. Kasprzyk, and W. V. Srubar, "Computational design optimization of concrete mixtures: a review," Cement and Concrete Research, vol. 109, pp. 42-53, 2018.

[18] S. Sarıdemir and Ü. Ağbulut, "Combustion, performance, vibration and noise characteristics of cottonseed methyl ester-diesel blends fuelled engine," Biofuels, 2019.

[19] Ü. Ağbulut, "Mathematical calculation and experimental investigation of expanded perlite based heat insulation materials' thermal conductivity values," Journal of Thermal Engineering, vol. 4, no. 5, pp. 2274-2286, 2018.

[20] M. A. Getahun, S. M. Shitote, and Z. C. Abiero Gariy, "Artificial neural network based modelling approach for strength prediction of concrete incorporating agricultural and construction wastes," Construction and Building Materials, vol. 190, pp. 517-525, 2018.

[21] M. Nematzadeh, J. Dashti, and B. Ganjavi, "Optimizing compressive behavior of concrete containing fine recycled refractory brick aggregate together with calcium aluminate cement and polyvinyl alcohol fibers exposed to acidic environment," Construction and Building Materials, vol. 164, pp. 837-849, 2018.

[22] F. Köksal, Y. Şahin, O. Gencel, and İ. Yiğit, "Fracture energybased optimisation of steel fibre reinforced concretes," Engineering Fracture Mechanics, vol. 107, pp. 29-37, 2013.

[23] M. Muthukumar and D. Mohan, "Optimization of mechanical properties of polymer concrete and mix design recommendation based on design of experiments," Journal of Applied Polymer Science, vol. 94, no. 3, pp. 1107-1116, 2004.

[24] B. E. Jimma and P. R. Rangaraju, "Chemical admixtures dose optimization in pervious concrete paste selection-a statistical approach," Construction and Building Materials, vol. 101, pp. 1047-1058, 2015.

[25] M. Muthukumar, D. Mohan, and M. Rajendran, "Optimization of mix proportions of mineral aggregates using box behnken design of experiments," Cement and Concrete Composites, vol. 25, no. 7, pp. 751-758, 2003.

[26] P. K. Mehta and P. J. M. Monteiro, Concrete, Microstructure, Properties, and Materials, McGraw-Hill, New York, NY, USA, 3rd edition, 2006.

[27] K. Kiattikomol, C. Jaturapitakkul, S. Songpiriyakij, and S. Chutubtim, "A study of ground coarse fly ashes with different finenesses from various sources as pozzolanic materials," Cement and Concrete Composites, vol. 23, no. 4-5, pp. 335-343, 2001.

[28] P. Onprom, K. Chaimoon, and R. Cheerarot, "Influence of bottom ash replacements as fine aggregate on the property of cellular concrete with various foam contents," Advances in Materials Science and Engineering, vol. 2015, Article ID 381704, 11 pages, 2015. 